\title{
Area selection using magnetotellurics: Examples from southern Africa
}

\author{
Alan G. Jones ${ }^{1}$, Mark R. Muller ${ }^{1}$, Mark P. Hamilton ${ }^{1,10,13}$, Marion P. Miensopust ${ }^{1}$, Xavier \\ Garcia ${ }^{1}$, Rob L. Evans ${ }^{2}$, Patrick Cole ${ }^{3}$, Tiyapo Ngwisanyi ${ }^{4}$, Dave Hutchins ${ }^{5}$, C.J. Stoffel \\ Fourie $^{6}$, Moctar Doucoure ${ }^{7}$, Andy Mountford ${ }^{8}$, Wayne Pettit ${ }^{9}$, Sue Webb ${ }^{10}$, Jan Wasborg ${ }^{11}$, \\ and The SAMTEX Team ${ }^{12}$
}

\begin{abstract}
1: Dublin Institute for Advanced Studies, 5 Merrion Square, Dublin, Ireland; 2: Department of Geology and Geophysics, Woods Hole Oceanographic Institution, Clark South 172, 360 Woods Hole Road, Woods Hole, Massachusetts, 02543-1542, U.S.A.; 3: Council for Geoscience, 280 Pretoria Street, Silverton, Pretoria 0001, RSA; 4: Geological Survey of Botswana, Private Bag 14, Lobatse, Botswana; 5: Geological Survey of Namibia, 1 Aviation Road, Windhoek, Namibia; 6: Council for Scientific and Industrial Research, Pretoria, RSA; 7: De Beers Group Services, Private Bag X01, Southdale 2135, South Africa; 8: Rio Tinto Mining and Exploration, London, U.K.; 9: BHP Billiton, Johannesburg, RSA; 10: University of the Witwatersrand, 6 Hollard Street, Johannesburg 2001, RSA; 11: ABB AB, HVDC, Ludvika, SE-77180, Sweden; 12: Other members of the SAMTEX team include: Louise Collins, Colin Hogg, Clare Horan, Jessica Spratt, Gerry Wallace (DIAS), Alan D. Chave (WHOI), Janine Cole, Raimund Stettler (CGS), G. Tshoso (GSB), Ed Cunion (RTME), David Khosa (BHPB) and Pieter-Eward Share (CSIR); 13: Now at EMGS, Stiklestadveien 1, $N$-7041 Trondheim, Norway.
\end{abstract}

\section{Introduction}

The Southern African Magnetotelluric Experiment (SAMTEX) project is imaging the properties and geometries of the continental lithosphere below southern Africa using the natural-source electromagnetic method magnetotellurics. Electrical conductivity is highly sensitive to ambient temperature (e.g., Ledo and Jones, 2005) and to the presence of an interconnected conducting phase, such as a solid phase like graphite or sulphides (e.g., Jones et al., 2003) or a fluid phase like partial melt (e.g., Park and Ducea, 2003), or bound water through hydrogen diffusion (e.g., Hirth et al., 2000). Given these circumstances, deep-probing magnetotellurics can aid in area selection for potential diamondiferous prospective regions (Jones and Craven, 2004).

\section{The SAMTEX project}

The SAMTEX project was initially conceived in 1996 in discussions between Alan Jones (then at the Geological Survey of Canada), Leo Fox (President of Phoenix Geophysics) and Eddie Kostlin (then with Anglo). Interest was expressed by Anglo/DeBeers in "testing” out the capabilities of deep-probing magnetotellurics as an effective area selection tool for diamondiferous regions. This interest grew as the diamond exploration community became more aware of the potential of the method through presentations (Jones, 1997, 1999a, 2000; Jones and Craven, 2001) and short courses (Jones, 1999b, 2001), and as the results from the MT studies on the Slave craton came out (Jones et al., 1999, 2001, 2003; Jones and Ferguson, 1997). Funding made available by DeBeers to Jones and Phoenix in 1998 and 1999 for a pilot survey could not be accessed due to GSC internal issues and lack of access to equipment. Serendipitously, a 1998 meeting between Jones and Edgar Stettler (then at the Council for Geoscience) led to what has proven to be an absolutely invaluable collaboration with CGS through all phases of
SAMTEX. In November, 2002 a proposal was submitted to the Continental Dynamics programme of the National Science Foundation led by Rob Evans (WHOI) with four SAMTEX partners;

1) The Dublin Institute for Advanced Studies

2) Woods Hole Oceanographic Institution

3) The Council for Geoscience, and

4) De Beers Group Services.

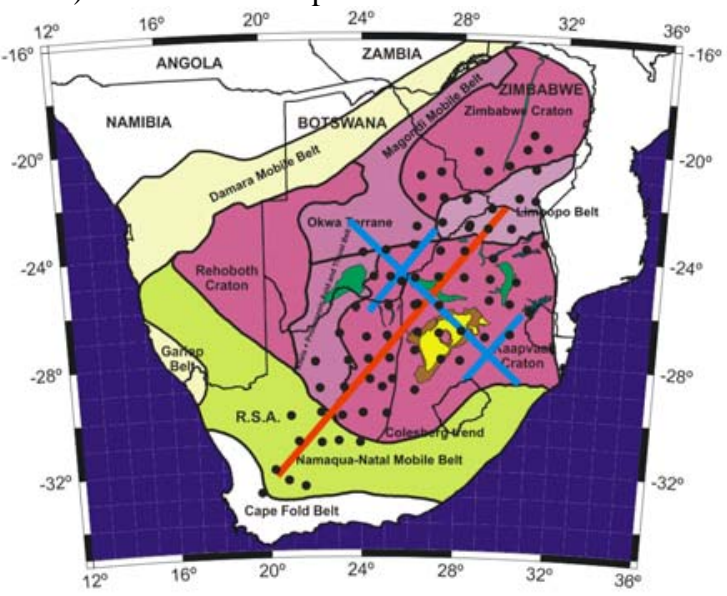

Figure 1: SAMTEX acquisition plan proposed to NSF in 2003. Red: Year 1. Blue: Year 2. SASE stations in black. The interpreted tectonic subdivision is from S. Webb (unpubl.).

The proposal was for a relatively simple experiment to acquire data along two orthogonal profiles in predominantly South Africa during two phases of acquisition (Fig. 1). The project was intended to follow the highly successful Kaapvaal Project, particularly the Southern African Seismic Experiment (SASE) array. The proposal was funded in the Spring of 2003 with the first phase of fieldwork in the Autumn of 2003. Besides the NSF, other funding came from DeBeers and from a 
Department of Science and Technology grant to the Council for Geoscience.

As the SAMTEX project has progressed, more partners have joined the consortium, which now comprises a total of eleven members - the original four plus:

5) Geological Survey of Namibia

6) The University of the Witwatersrand

7) Geological Survey of Botswana

8) Rio Tinto Mining and Exploration

9) BHP Billiton

10) Council for Scientific and Industrial Research

11) ABB Sweden.

and additional funding was obtained for Phase III from Science Foundation Ireland.

The new partners brought in both logistical and financial support so we have now completed four far larger phases of acquisition, rather than the two planned (compare Figs. 1 and 2). In addition, DeBeers has donated proprietary MT data to the SAMTEX project. In total, the SAMTEX dataset now comprises data from a total of more than 700 sites over an area in excess of a million square kilometres. As such, this is by far the largest regional-scale MT project ever undertaken.

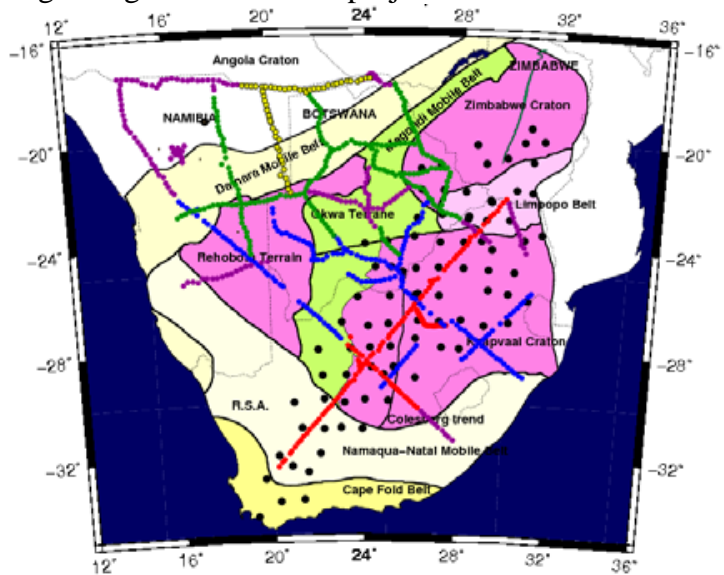

Figure 2: SAMTEX MT station locations. Phase I - red; Phase II - blue; Phase III - green; Phase IV - purple; DeBeers - yellow; SASE sites - black. The interpreted tectonic subdivision is from S. Webb (unpubl.).

\section{Map construction}

Preliminary information can be obtained rapidly through constructing maps of various parameters obtained from the magnetotelluric impedance tensors. Conventionally, these maps are created at given periods. However, such maps can be highly misleading if crustal conductivity varies significantly across the region (Jones, 2006; Hamilton et al., 2006). This problem is extreme for southern Africa. Along the 2003 main NE-SW Kaapvaal craton profile periods of around 1 second penetrate to the base of the crust at stations in the centre of the craton but for the same penetration periods of 1,000 seconds or greater are needed at the SW end. Thus, it is necessary to perform an approximate depth conversion prior to constructing the maps.

\section{Resistivity Depth Images}

An example map (Fig. 3) is the resistivity image at a depth of approx, $200 \mathrm{~km}$ (approx. base of the litho- sphere). Also plotted on the map are the locations of known kimberlites, and, if known, whether diamondiferous (red) or not (green). Mantle lithospheric rocks comprising olivine, pyroxenes and garnet at cratonic P$\mathrm{T}$ conditions should have resistivities well in excess of

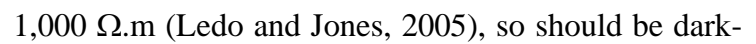
green to blue. The hotter colours, yellows to reds, are indicative of either hotter conditions and/or the presence of a conducting component. (The map has been constructed from the data from Phases I-III. More upto-date maps will be shown at the $9^{\text {th }}$ IKC.)

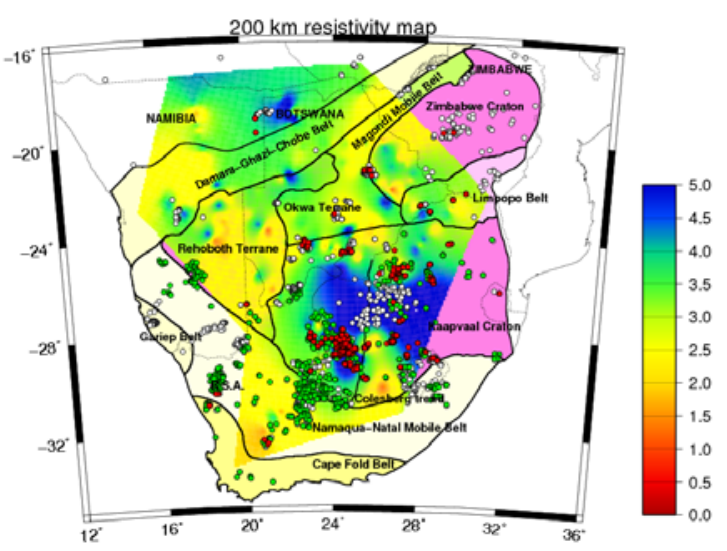

Figure 3: Resistivity image at a depth of $200 \mathrm{~km}$. The colours are resistivity in log10 units. Kimberlites are shown by circles, with known diamondiferous ones in red, known nondiamondiferous ones in green, and unkown (to us!) in white.

The maps show the Kaapvaal Craton exhibits highly resistive lithosphere throughout, and resistive lithosphere is associated with the Congo/Angola Craton and with parts of the Zimbabwe Craton. In addition, the map shows low resistivity for the Rehoboth Terrane, thought by some to be an Archean craton. There is an excellent spatial correlation between the resistive regions and diamondiferous kimberlites. One anomalous result is the purported diamondiferous kimberlite in the Rietfontein cluster on the Namibian/South African border, but this is now known to be a bicycle diamond.

\section{Comparison with SASE results}

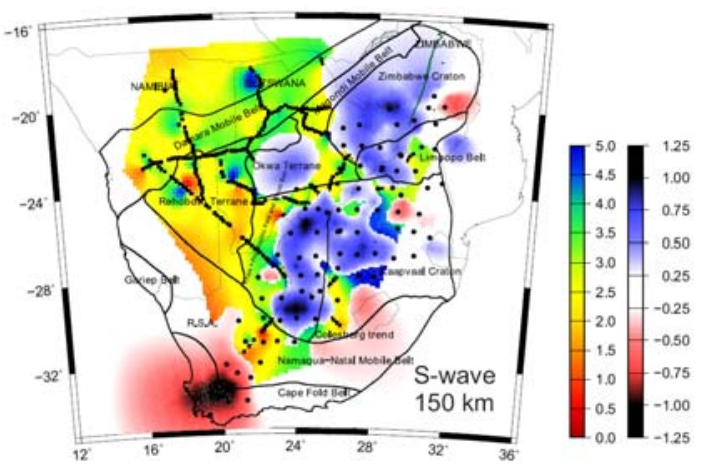

Figure 4: Comparison of resistivity and Vs velocity perturbations at $150 \mathrm{~km}$. Resistivity is on a $\log 10$ scale in rainbow colours, and the velocity perturbations are given in $\%$. 
Figure 4 shows a comparison with our resistivity image for a depth of $150 \mathrm{~km}$ and the shear-wave body wave tomographic perturbation model of Fouch et al. (2004). Generally, where there is high velocity there is high resistivity, and vice-versa. Other comparisons with both body wave and surface wave results also exhibit considerable correlation between the regional results from MT and those obtained from teleseismic models.

\section{Models}

A more robust product from SAMTEX is a model of the subsurface, rather than an image. Modelling is progressing on a variety of profiles. An early model for the main Kaapvaal Craton line is shown in Fig. 5, together with the inferred base of the lithosphere. Note the thin lithosphere to the SW (beneath the Namaqua-Natal Mobile Belt), thikh lithosphere in the centre of the craton, and transitional lithosphere inbetween, where most of the diamondiferous kimberlites are.

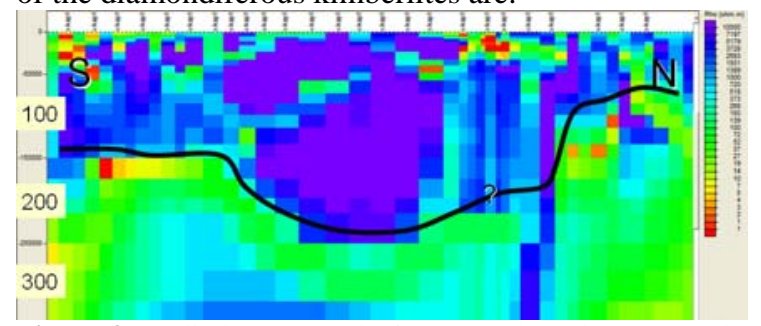

Figure 3: Preliminary model of the MT data along the main 2003 profile with the inferred base of the lithosphere.

\section{Acknowledgments}

Many, many, many people on three continents contributed to the huge achievement in data acquisition of the SAMTEX project. Besides the consortium members and their staffs, we wish to acknowledge Phoenix Geophysics's many contributions, and the Geological Survey of Canada and the U.S. EMSOC access to instrumentation. We especially thank our funding sponsors; the CD panel of the U.S. NSF, the RSA's Department of Science and Technology, and Science Foundation Ireland. Finally, we thank the people of Southern Africa for their generous warm spirit allowing weird scientists on their land.

\section{References}

Fouch, M.J., D.E. James, J. C. van Decar, S. van der Lee, and the Kaapvaal Seismic Group, 2004. Mantle seismic structure beneath the Kaapvaal and Zimbabwe Cratons. South African Journal of Geology, 107, 33-44.

Hamilton, M.P., A.G. Jones, R.L. Evans, S. Evans, S. Fourie, X. Garcia, A. Mountford, J.E. Spratt, and the SAMTEX Team, 2006. Electrical anisotropy structure of South African lithosphere compared with seismic anisotropy from shear-wave splitting analyses. Physics of the Earth and Planetary Interiors, 158, 226-239.

Hirth, G., R.L. Evans, and A.D. Chave, 2000. Comparison of continental and oceanic mantle electrical conductivity: Is the Archean lithosphere dry? Geochemistry, Geophysics, and Geosystems, 1, 2000 GC000048.
Jones, A.G., 1997. Imaging the continental upper mantle using electromagnetic methods. Contributed paper at: Workshop on Continental Roots, Harvard Univ., Cambridge, U.S.A., Oct 10-13.

Jones, A.G., 1999a. Imaging the continental upper mantle using electromagnetic methods. Lithos, 48, 57-80.

Jones, A.G., 1999b. Information about the continental mantle from deep electromagnetic studies. Lecture presented as part of the one-day Short Course on Geophysical and Geochemical Imaging of Canada's Upper Mantle organised by A.G. Jones and held in Yellowknife, NWT, Canada, on 27 November.

Jones, A.G., 2000. Lighting up the mantle: Information from electromagnetic waves about the continental mantle lithosphere and asthenosphere. Invited paper at: Cordilleran Roundup, Vancouver, B.C., January 24-28.

Jones, A.G., 2001. Information about the continental mantle from deep electromagnetic studies. Lecture presented as part of the one-day Short Course on Geophysical and Geochemical Imaging of Canada's Upper Mantle organised by A.G. Jones and held in Toronto, Ont., Canada, on 10 March.

Jones, A.G., 2006. Electromagnetic interrogation of the anisotropic Earth: Looking into the Earth with polarized spectacles. Physics of the Earth and Planetary Interiors, 158, 281-291.

Jones, A.G., and J.A. Craven, 2001. Carbon in the mantle? The electromagnetic responses of the Slave and Superior cratons compared and contrasted. Contributed paper at: Yellowknife Geoscience Forum, Yellowknife, NWT, Canada, 21-23 November.

Jones, A.G., and J.A. Craven, 2004. Area selection for diamond exploration using deep-probing electromagnetic surveying. Lithos, 77, 765-782.

Jones, A.G. and I.J. Ferguson, 1998. Northern lights and diamonds: Imaging the Slave cratonic lithosphere using very long period electromagnetic experiments. Contributed paper at: Yellowknife Geoscience Forum, Yellowknife, NWT, Canada, November 25-27.

Jones, A.G., and others 1999. Slave EM. Contributed paper at: Yellowknife Geoscience Forum, Yellowknife, NWT, Canada, 24-26 November.

Jones, A.G., I.J. Ferguson, A.D. Chave, A.D., R.L. Evans, and G.W. McNeice, 2001. The electric lithosphere of the Slave craton. Geology, 29, 423-426.

Jones, A.G., P. Lezaeta, I.J. Ferguson, A.D. Chave, R.L. Evans, X. Garcia, and J. Spratt, 2003. The electrical structure of the Slave craton. Lithos, 71, 505527.

Ledo, J., and A.G. Jones, 2005. Temperature of the upper mantle beneath the Intermontane Belt, northern Canadian Cordillera, determined from combining mineral composition, electrical conductivity laboratory studies and magnetotelluric field observations. Earth and Planetary Science Letters, 236, 258-268.

Park S.K., and M.N. Ducea, 2003. Can in situ measurements of mantle electrical conductivity be used to infer properties of partial melts? Journal of Geophysical Research, 108, EPM 14-1 to EPM 14-12, Art. No. 2270, doi: 10.1029/2002JB001899. 